\title{
Site-specific induction of intestinal hypoxia-inducible factor-1 $\alpha$ after hemorrhagic shock
}

\author{
HIROYUKI NISHIE $^{1}$, TORU TAKAHASHI ${ }^{1}$, KAZUYOSHI INOUE $^{1}$, HIROKO SHIMIZU $^{1}$, HIROSHI MORIMATSU ${ }^{1}$, \\ YUICHIRO TODA ${ }^{1}$, EMIKO OMORI ${ }^{1}$, REIKO AKAGI ${ }^{2}$, HIROSHI KATAYAMA $^{1}$ and KIYOSHI MORITA ${ }^{1}$ \\ ${ }^{1}$ Department of Anesthesiology and Resuscitology, Okayama University Medical School, Okayama 700-8558; \\ ${ }^{2}$ Department of Pharmacy, Yasuda Women's University, Hiroshima 731-0153, Japan
}

Received November 25, 2008; Accepted January 22, 2009

DOI: $10.3892 / \mathrm{mmr} 000000075$

\begin{abstract}
The intestine is a major target organ in hemorrhagic shock (HS)-induced tissue injury. Hypoxia-inducible factor (HIF)- $1 \alpha$ is the primary transcription factor responsible for regulating cellular response to changes in oxygen tension. Since HS is an acute hypoxic insult, the present study examined changes in the gene expression of HIF-1 $\alpha$ in various regions of the intestine, as well as the distribution of HIF-1 $\alpha$ protein in the intestinal cells of a rat model of HS. Levels of HIF- $1 \alpha$ mRNA were marginally detectable in the intestine of sham-operated control animals, but obviously induced following HS. Duodenal, jejunal and colonic levels of HIF-1 $\alpha$ mRNA robustly increased and reached a maximum during the ischemic phase of HS, followed by a rapid decrease almost to control levels during the early phase of resuscitation. The induction of HIF- $1 \alpha$ mRNA was maximal in the duodenum. In contrast to the duodenum, jejunum and colon, in the ileum the HIF- $1 \alpha$ mRNA level did not increase after HS. Consistent with enhanced HIF-1 $\alpha$ gene expression, HIF-1 $\alpha$ protein was expressed in the mucosal cells of the duodenum, jejunum and colon, but not in the ileum following HS. These findings indicate that intestinal HIF-1 $\alpha$ expression was up-regulated at both the transcriptional and protein level in a site-specific manner in this rat model of HS. Differential regulation of HIF-1 $\alpha$ expression along the longitudinal axes of the intestine might be a determinant of the adaptive response to HSinduced intestinal damage.
\end{abstract}

\section{Introduction}

Hemorrhagic shock (HS) induces a systemic inflammatory response that results in multiple organ failure with significant

Correspondence to: Dr Toru Takahashi, Department of Anesthesiology and Resuscitology, Okayama University Medical School, 2-5-1 Shikata-cho, Okayama 700-8558, Japan

E-mail: takatoru@cc.okayama-u.ac.jp

Key words: hypoxic insult, intestine, multiple organ failure, systemic inflammation mortality and morbidity (1). The intestine is considered to contribute to the establishment of multiple organ damage, both as an instigator of systemic inflammation as well as a victim of end-organ injury (2).

Hypoxia-inducible factor (HIF)- $1 \alpha$ is a basic helix-turnhelix transcription factor that controls cellular adaptation to hypoxia, including erythropoiesis, angiogenesis, vasodilatation and anaerobic metabolism (3). Previous studies have indicated that hypoxic insult activates HIF-1 $\alpha$ mRNA and protein expression in various organs in a tissue-specific manner (4-6). However, few studies have investigated the effect of hypoxia on the expression of intestinal HIF- $1 \alpha$.

Here, we examined the effect of HS on HIF-1 $\alpha$ expression in the intestine at the transcriptional and protein level in various regions of the intestine, because HS results in tissue hypoxia. HIF-1 $\alpha$ mRNA and protein expression was found to be increased in the mucosal cells of the duodenum, jejunum and colon, but not in the mucosal cells of the ileum during the early ischemic phase of HS, indicating that the regulation of HIF-1 $\alpha$ expression in the intestinal mucosa is site-specific. These findings suggest that the intestine adaptively responds to hypoxic insult by HS in a regiospecific manner.

\section{Materials and methods}

Animals. All procedures conformed to the guidelines for the care and use of laboratory animals established by the Animal Use and Care Committee of Okayama University Medical School. Male Sprague-Dawley rats weighing 380-420 g purchased from Charles River Laboratories Japan Inc. (Yokohama, Japan) were housed in a temperature-controlled $\left(25^{\circ} \mathrm{C}\right)$ room with an alternating 12-h light/12-h dark cycle, and were given water and a chow diet ad libitum until the start of the experiments.

Experimental protocol. Rats anesthetized with intraperitoneal sodium pentobarbital $(50 \mathrm{mg} / \mathrm{kg})$ underwent a sham procedure or HS as described (7). In brief, heparinized polyethylene tubes were inserted into the left femoral artery to measure blood pressure and into the left femoral vein to induce hemorrhage by bleeding into a heparinized syringe (10 units $/ \mathrm{ml})$ over a period of $15 \mathrm{~min}$ to achieve a mean arterial blood pressure of $30 \pm 5 \mathrm{mmHg}$. This level of blood pressure was maintained for $60 \mathrm{~min}$ by further blood withdrawal or by re-infusion with the 
A
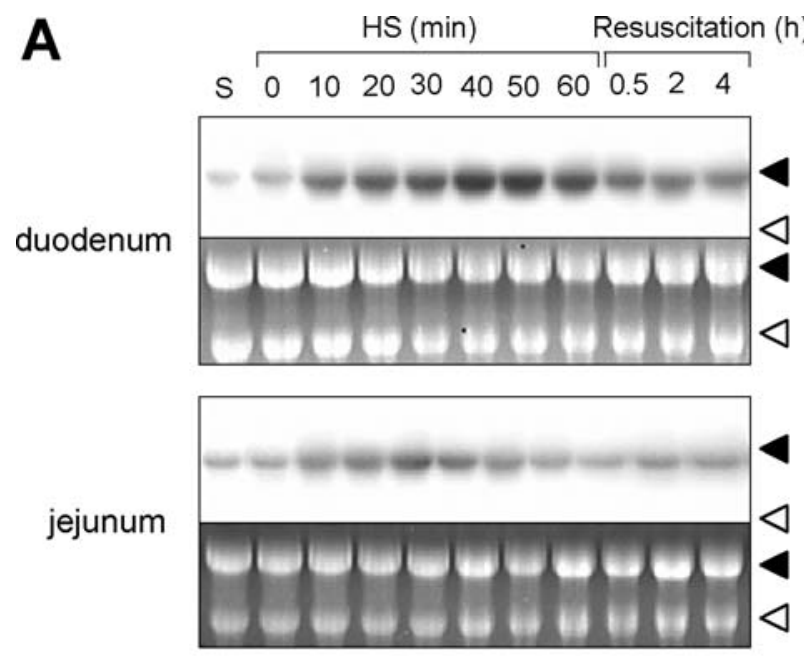

ileum

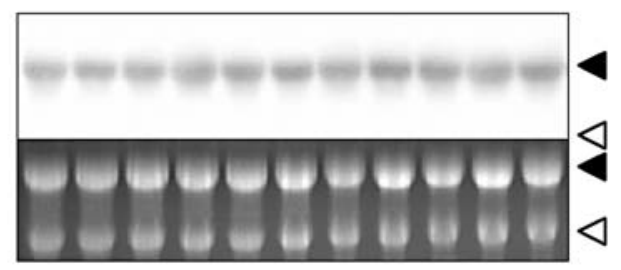

colon

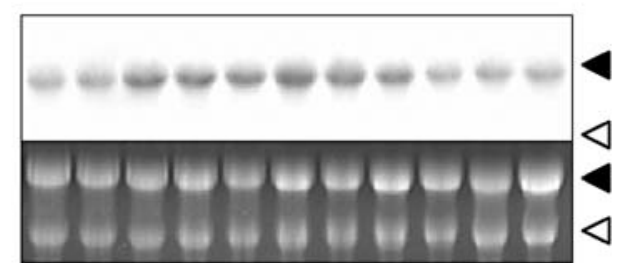

B
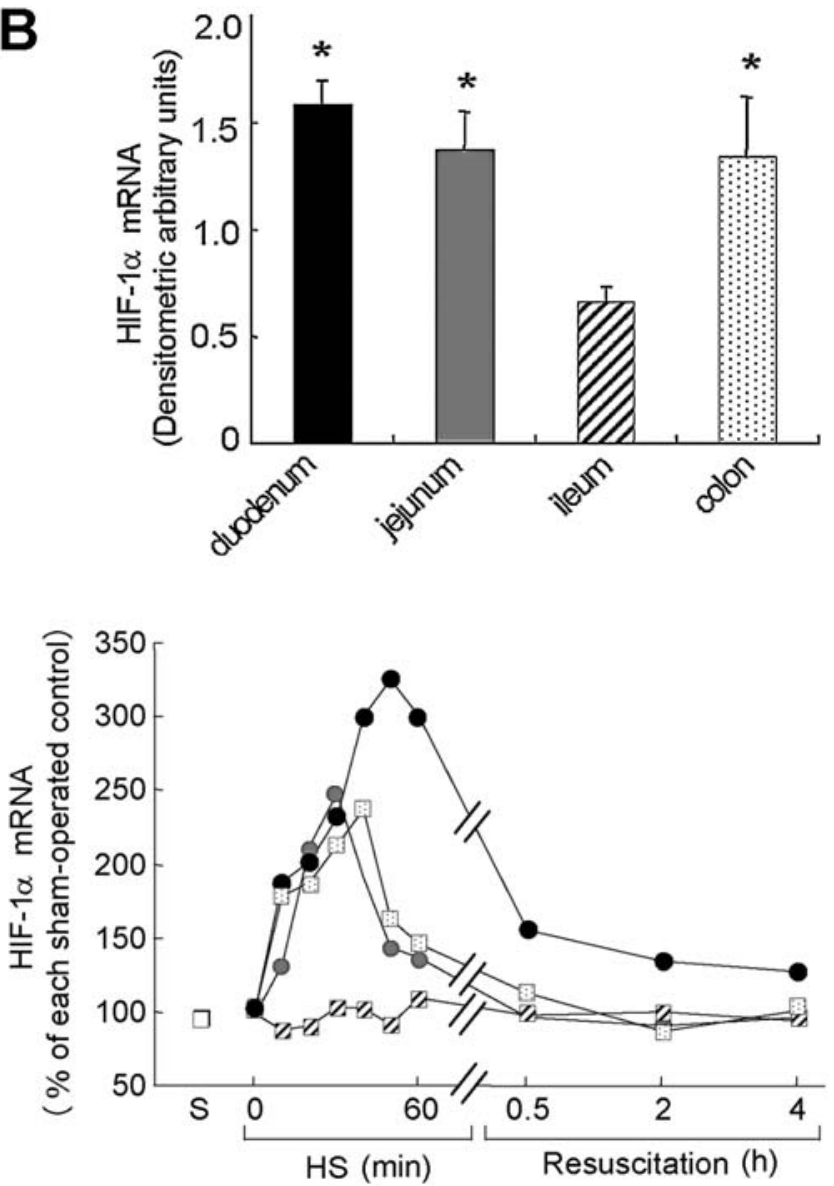

Figure 1. Effect of hemorrhagic shock (HS) on hypoxia-inducible factor (HIF)- $1 \alpha$ gene expression in various intestinal regions. Rats were sacrificed at 0 , 10, 20,30, 40, 50 and $60 \mathrm{~min}$ after the onset of HS, and at 0.5, 2 and $4 \mathrm{~h}$ after the start of resuscitation. Intestines were excised and the duodenum, jejunum, ileum and colon were dissected for Northern blotting as described in Materials and methods. (A) Northern blots of total RNA (20 $\mu \mathrm{g})$ hybridized with [ $\left.\alpha{ }^{-32} \mathrm{P}\right] \mathrm{dCTP}-$ labeled HIF-1 $\alpha$ cDNA. Loading control, same total RNA stained with ethidium bromide. Filled arrowhead, 28S ribosomal RNA; open arrowhead, 18S ribosomal RNA; S, sham-operated control animals. Results are typical of three independent experiments. (B) Levels of HIF-1 $\alpha$ mRNA expressed as ratios (\%) of respective sham-operated controls. Filled circles, duodenum; gray circles, jejunum; shaded boxes, ileum; dotted boxes, colon. Insets: maximal levels of HIF-1 $\alpha$ mRNA during and after HS in various regions of the intestine expressed as arbitrary densitometric units. Data are presented as the means \pm SEM $(\mathrm{n}=3) .{ }^{*} \mathrm{p}<0.05$ vs. ileum.

shed blood. At this point, the animals were resuscitated over a period of $15 \mathrm{~min}$ by returning all shed blood followed by sterile saline as required to restore blood pressure to the baseline level. The sham group underwent all instrumentation procedures, but blood was not collected. The animals breathed spontaneously and naturally throughout the experiment. To maintain body temperature within physiological range, all manipulations were conducted on a heating pad, while body temperature was continuously monitored rectally. The rats were also monitored by continuous electrocardiography. At 0 , 10, 20, 30, 40, 50 and $60 \mathrm{~min}$ after the onset of HS, and at 0.5, 2 , and $4 \mathrm{~h}$ after the start of resuscitation, the entire intestine was excised and the duodenum, jejunum, ileum and colon were dissected as described (8), gently rinsed in physiological saline, snap-frozen in liquid nitrogen and stored at $-80^{\circ} \mathrm{C}$ until being used for RNA preparation.

RNA isolation and Northern blot analysis. Total RNA isolated from rat tissues using Tri-Reagent ${ }^{\mathrm{TM}}$ (Sigma Chemical Co., St. Louis, MO) according to the manufacturer's protocol was subjected to Northern blotting as described (8), then $20 \mu \mathrm{g}$ of the total RNA was resolved by electrophoresis on $1.2 \%(\mathrm{w} / \mathrm{v})$ agarose gels containing $6.5 \%$ (v/v) formaldehyde. Resolved bands were blotted onto a Bio-Rad Zeta-Probe ${ }^{\mathrm{TM}}$ membrane (Bio-Rad Laboratories, Richmond, CA), hybridized with $\left[\alpha^{-32} \mathrm{P}\right] \mathrm{dCTP}-$ labeled mouse HIF-1 $\alpha$ cDNA (9) constructed in the pBlueScript Vector (Stratagene, La Jolla, CA), then washed under stringent conditions. The membrane was exposed to radiography film (Fujifilm Medical, Tokyo, Japan) with an intensifying screen at $-70^{\circ} \mathrm{C}$, and autoradiographs and levels of $18 \mathrm{~S}$ ribosomal RNA were quantified using an image scanner (GelPrint $^{\mathrm{TM}}$ 2000i, Genomic Solutions, Ann Arbor, MI) and computerized image analysis software (Basic Quantifier ${ }^{\mathrm{TM}}$, version 3.0, Genomic Solutions). Relative amounts of radiolabeled cDNA that hybridized to the blots were normalized to $18 \mathrm{~S}$ ribosomal RNA levels for loading errors.

Immunohistochemistry. Sections were immunohistochemically analyzed as described (8). Intestinal tissue was fixed in $10 \%$ neutral buffered formalin, embedded in paraffin and cut into 4- to 6- $\mu \mathrm{m}$ sections. The enzymatic activities of endogenous peroxidases in deparaffinized and dehydrated sections were blocked with $3 \%$ hydrogen peroxide. Subsequently, the sections were incubated overnight at $4^{\circ} \mathrm{C}$ with a rabbit anti- 
A

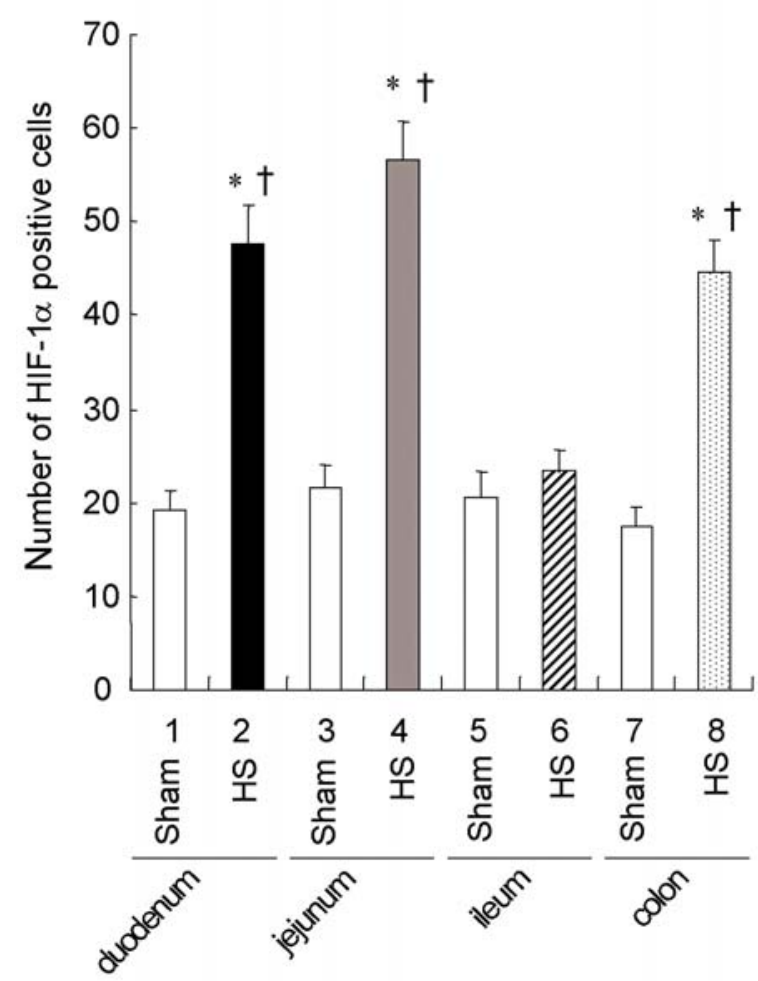

B
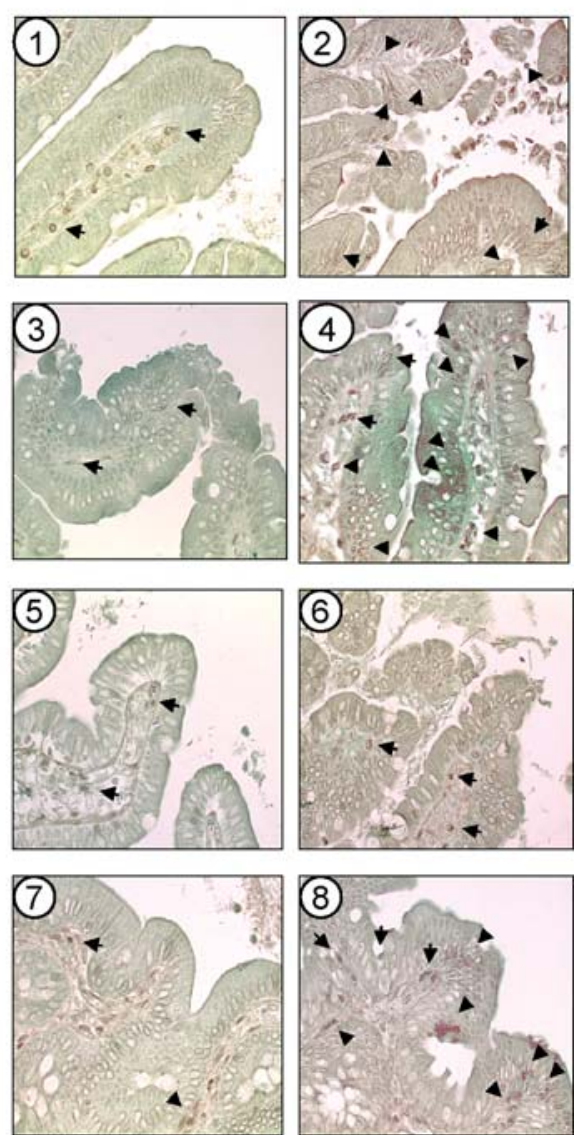

Figure 2. Immunohistochemistry of hypoxia-inducible factor (HIF)-1 $\alpha$ in various intestinal regions following hemorrhagic shock (HS). Immunohistochemical analysis of HIF-1 $\alpha$ in intestinal sections $40 \mathrm{~min}$ after the onset of HS or sham operation using primary rabbit polyclonal anti-rat HIF-1 $\alpha$ antibody. See Materials and methods for details of immunohistochemical staining. (A) Number of HIF-1 $\alpha$-positive cells in five non-consecutive intestinal mucosal sections per rat at a magnification of $\mathrm{x} 200$. Sham, sham-operated control animals; HS, HS-treated animals. Data are presented as the means \pm SEM ( $\mathrm{n}=6$ ). * $\mathrm{p}<0.01 \mathrm{vs.} \mathrm{HS-treated}$ ileum. ${ }^{\dagger} \mathrm{p}<0.01$ vs. regional matched Sham. (B) Each photograph is representative of six independent experiments. Arrowheads indicate positive staining for $\mathrm{HIF}-1 \alpha$ protein. Photograph numbers correspond to the numbers in panel A (original magnification, $\mathrm{x} 400$ ).

rat HIF-1 $\alpha$ polyclonal antibody (Novus Biologicals Inc., Littleton, CO). Antigen-antibody reactions were detected using a dextran polymer reagent conjugated with peroxidase and a secondary antibody (Dako EnVision ${ }^{\mathrm{TM}}+$, DakoCytomation A/S, Copenhagen, Denmark), then color was developed with 3,3'-diaminobenzidine and the sections were counterstained with Mayer's hematoxylin. The control for nonspecific staining included normal rabbit serum. The number of HIF-1 $\alpha$-positive cells was counted in five non-consecutive sections from each rat at a magnification of $\mathrm{x} 200$ by two independent investigators (H.S. and E.O.) in a blinded manner.

Statistical analysis. Data were statistically evaluated by the analysis of variance followed by Scheffé's F-test using Statview software (Abacus Concepts, Berkeley, CA). Differences were considered significant at $\mathrm{p}<0.05$. Data are presented as the means \pm SEM.

\section{Results}

Time courses of intestinal HIF-1a mRNA after HS. We examined levels of HO-1 mRNA in several regions of the intestine after HS. In sham-operated control animals, HIF-1 $\alpha$ mRNA was only marginally detectable in the duodenum, jejunum, ileum and colon (Fig. 1). In contrast, HIF-1 $\alpha$ mRNA levels were obviously increased after HS in the duodenum, jejunum and colon. Duodenal HIF-1 $\alpha$ mRNA levels started to increase $10 \mathrm{~min}$ after $\mathrm{HS}$, reached a maximum at $50 \mathrm{~min}$, then rapidly decreased to $40 \%$ of the maximal level at $30 \mathrm{~min}$ after the start of resuscitation (Fig. 1). Jejunal and colonic HIF- $1 \alpha$ mRNA levels similarly increased at 20 min after HS and reached a maximum at 30 and 40 min, respectively, then rapidly declined almost to basal levels $30 \mathrm{~min}$ after resuscitation (Fig. 1). Levels in the ileum hardly increased after HS. Levels of maximally induced HIF- $1 \alpha$ mRNA in the duodenum, jejunum and colon were approximately 2.5-, 2- and 2-fold higher, respectively, than in the ileum (Fig. 1).

Intestinal HIF-1 $\alpha$ protein expression after HS. Since Northern blot analysis revealed the expression of intestinal HIF- $1 \alpha$ mRNA in HS animals, we examined the expression as well as the localization of HIF- $1 \alpha$ protein in the intestinal tissue $40 \mathrm{~min}$ after the onset of HS by immunohistochemical analysis. Few HIF-1 $\alpha$-positive cells were detected in the intestines of shamoperated control animals (Fig. 2), but numbers were obviously increased in the duodenum, jejunum and colon after HS (Fig. 2). This finding was consistent with enhanced HIF-1 $\alpha$ gene expression in HS animals. Mucosal cells emitted intense 
HIF-1 $\alpha$ signals, whereas the number of HO-1-positive cells did not increase in the ileum after HS (Fig. 2). Sections of the intestine of HS animals treated with non-immune rabbit serum were negative (data not shown).

\section{Discussion}

Our study demonstrated that HIF- $1 \alpha$ mRNA and protein levels were increased in the intestinal mucosa of rats during the ischemic phase of HS. An important novel finding is that HIF- $1 \alpha$ induction after HS was remarkably site-specific, in that it was obviously increased in the duodenum, jejunum and colon, but not in the ileum. These findings suggest that adaptation to hypoxic stress differs regionaly in the intestine. Further studies should elucidate the mechanism and significance of such heterogeneous regiospecific induction.

Figs. 1 and 2 showed that HIF- $1 \alpha$ mRNA and protein levels in the mucosal cells of the duodenum, jejunum and colon were rapidly and obviously increased during the early ischemic phase of HS. In contrast, these levels in the ileum were neither increased nor influenced by HS. Thus, HIF-1 $\alpha$ expression was site-specific. Koury et al reported that ileal nuclear HIF-1 $\alpha$ protein levels were increased after HS for 90 min plus laparotomy (10). However, their animal models underwent more serious insult than ours. Furthermore, they did not compare HIF-1 $\alpha$ expression levels in the ileum with those of other intestinal regions, such as the duodenum, jejunum and colon. It therefore remains unclear whether ileal HIF-1 $\alpha$ induction was greater than that in other intestinal regions.

Hemorrhage results in varying degrees of decrease in blood flow in subregions of the intestine (11). The rate of metabolism of glucose to lactate also differs distinctly depending on intestinal region (12). Thus, changes in regional blood flow and differences in cellular oxygen consumption may affect the degree of cellular hypoxia in various regions of the intestine. Moreover, previous studies have shown that tissue-specific changes in mRNA and protein synthesis are integral to survival under hypoxic/anoxic stress $(13,14)$. Taken together, these factors might contribute to the site-specific induction of HIF- $1 \alpha$ expression. Similar to the intestine, recent reports indicate that HIF- $1 \alpha$ mRNA and protein expression induced by hypoxic insult is also regulated in a tissue-specific manner (4-6).

The biological significance of site-specific HIF- $1 \alpha$ induction in the intestine after HS remains obscure. The expression of various genes that participate in cellular adaptation to hypoxia, including erythropoiesis, angiogenesis, vasodilatation and anaerobic metabolism, is regulated by HIF-1 $\alpha$ (3). Among these genes is the one that encodes heme oxygenase-1 (HO-1), the rate-limiting enzyme in heme catabolism that is also known as heat shock protein (15). The critical role played by HIF- $1 \alpha$ in HO-1 induction during hypoxia was established based on the finding that hypoxia significantly increases the transcriptional rate of the ho- 1 gene, while hypoxia-dependent HO-1 expression is abolished in mutant cells lacking HIF-1 $\alpha$ DNA binding activity (16). We also demonstrated that HS results in the obvious induction of HO-1 in the mucosal cells of the duodenum, jejunum and colon, but not of the ileum (8), indicating that the sitespecific induction and cellular localization of HIF- $1 \alpha$ protein are entirely consistent with those of HO-1 induction after HS. Collectively, HIF-1 $\alpha$ might be involved in the site-specific induction of HO-1 in the intestine. Thus, our findings suggest that HIF-1 $\alpha$ induction constitutes a tissue-specific adaptive response to acute hypoxic insult by HS in the intestine.

\section{Acknowledgements}

This study was supported in part by grants from Grant-in-Aid for Scientific Research from the Ministry of Education, Culture, Sports, Science, and Technology of Japan.

\section{References}

1. Jarrar D, Chaudry IH and Wang P: Organ dysfunction following hemorrhage and sepsis: Mechanisms and therapeutic approaches (Review). Int J Mol Med 4: 575-583, 1999.

2. Hassoun HT, Kone BC, Mercer DW, Moody FG, Weisbrodt NW and Moore FA: Post-injury multiple organ failure: the role of the gut. Shock 15: 1-10,2001.

3. Semenza GL: HIF-1 and human disease: one highly involved factor. Genes Dev 14: 1983-1991, 2000.

4. Wiener CM, Booth G and Semenza GL: In vivo expression of mRNAs encoding hypoxia-inducible factor 1 . Biochem Biophys Res Commun 225: 485-488, 1996.

5. Stroka DM, Burkhardt T, Desbaillets I, Wenger RH, Neil DA, Bauer C, Gassmann M and Candinas D: HIF-1 is expressed in normoxic tissue and displays an organ-specific regulation under systemic hypoxia. FASEB J 15: 2445-2453, 2001.

6. Yu AY, Frid MG, Shimoda LA, Wiener CM, Stenmark K and Semenza GL: Temporal, spatial, and oxygen-regulated expression of hypoxia-inducible factor-1 in the lung. Am J Physiol 275: L818-L826, 1998.

7. Toda Y, Takahashi T, Maeshima K, Shimizu H, Inoue K, Morimatsu H, Omori E, Takeuchi M, Akagi R and Morita K: A neutrophil elastase inhibitor, sivelestat, ameliorates lung injury after hemorrhagic shock in rats. Int J Mol Med 19: 237-243, 2007.

8. Inoue K, Takahashi T, Uehara K, Shimuzu H, Ido K, Morimatsu H, Omori E, Katayama H, Akagi R and Morita K: Protective role of heme oxygenase 1 in the intestinal tissue injury in hemorrhagic shock in rats. Shock 29: 252-261, 2008.

9. Luo G, Gu YZ, Jain S, Chan WK, Carr KM, Hogenesch JB and Bradfield CA: Molecular characterization of the murine Hif-1 alpha locus. Gene Expr 6: 287-299, 1997.

10. Koury J, Deitch EA, Homma H, Abungu B, Gangurde P, Condon MR, Lu Q, Xu DZ and Feinman R: Persistent HIF1 alpha activation in gut ischemia/reperfusion injury: potential role of bacteria and lipopolysaccharide. Shock 22: 270-277, 2004.

11. Sobhian B, Jafarmadar M, Redl H and Bahrami S: Hemorrhageand resuscitation-related alterations in gastrointestinal circulation: effect of a low dose of L-NMMA. Shock 23: 243-247, 2005.

12. Hanson PJ and Parsons DS: The utilization of glucose and production of lactate by in vitro preparations of rat small intestine: effects of vascular perfusion. J Physiol 255: 775-795, 1976.

13. Smith RW, Houlihan DF, Nilsson GE and Alexandre J: Tissuespecific changes in RNA synthesis in vivo during anoxia in crucian carp. Am J Physiol 277: R690-R697, 1999.

14. Smith RW, Houlihan DF, Nilsson GE and Brechin JG: Tissuespecific changes in protein synthesis rates in vivo during anoxia in crucian carp. Am J Physiol 271: R897-R904, 1996.

15. Takahashi T, Shimizu H, Morimatsu H, Inoue K, Akagi R, Morita K and Sassa S: Heme oxygenase-1: a fundamental guardian against oxidative tissue injuries in acute inflammation. Mini Rev Med Chem 7: 745-753, 2007.

16. Lee PJ, Jiang BH, Chin BY, Iyer NV, Alam J, Semenza GL and Choi AM: Hypoxia-inducible factor-1 mediates transcriptional activation of the heme oxygenase-1 gene in response to hypoxia. J Biol Chem 272: 5375-5381, 1997. 